\title{
VALIDITY OF THE DIMENSIONS OF THE PAY SATISFACTION QUESTIONNAIRE: EVIDENCE OF DIFFERENTIAL PREDICTION
}

\author{
TIMOTHY A. JUDGE \\ Department of Personnel and Human Resource Studies \\ Cornell University
}

\begin{abstract}
The present study investigated the validity of the dimensions of the Pay Satisfaction Questionnaire (PSQ), in particular the degree to which the dimensions of the PSQ were differentially predicted by a number of antecedents. A series of tests supported dimensionality of the PSQ. Perhaps more importantly, a theoretical model was hypothesized and tested which was based on the assumption that different variables predict each of the four dimensions of pay satisfaction. Data was collected from a heterogeneous sample of sales, managerial, professionaltechnical, and nonexempt employees from a large multidivision corporation. A series of analyses indicated that the items from the PSQ loaded on their hypothesized dimensions, and the dimensions were empirically distinct. Furthermore, the dimensions were differentially predicted by a series of antecedents. This differential prediction evidence supports the validity of the dimensions of the PSQ in a more rigorous and comprehensive manner than has been produced by past research.
\end{abstract}

The recognition that pay satisfaction is a core component of job satisfaction is not new. In fact, conceptualizations and measurements of job satisfaction include pay satisfaction as a central element (Smith, Kendall, \& Hulin, 1969; Weiss, Dawis, England, \& Lofquist, 1967). Suggestions that pay satisfaction is a multidimensional construct came from Locke as early 1976. However, H. Heneman and Schwab $(1979,1985)$ were the first to explicitly hypothesize that pay satisfaction is multidimensional in nature. In developing the Pay Satisfaction Questionnaire (PSQ), $\mathrm{H}$. Heneman and Schwab (1985) initially hypothesized five dimensions of pay satisfaction: pay level, pay raises, benefits, structure, and administration. Based on initial factor analysis results, the validity of the level,

Funding for this project was provided by the Center for Advanced Human Resource Studies, Cornell University. The author would like to thank Al Brault, Bob Bretz, Renae Broderick, Lee Dyer, Barry Gerhart, and George Milkovich for their assistance with this project, and Melissa Arronte for assistance with data entry. Thanks also go to Bob Bretz, Lee Dyer, Barry Gerhart, George Milkovich, and three anonymous reviewers for comments on an earlier draft of this manuscript.

Correspondence and requests for reprints should be addressed to Timothy A. Judge, Department of Personnel and Human Resource Studies, Cornell University, 393 Ives Hall, Ithaca, NY 14853-3901. 
raises, and benefits dimensions was supported, but the structure and administration dimensions were combined. This four-factor solution was then replicated on another sample of workers. Subsequent work has supported the multidimensional nature of pay satisfaction, but has reached divergent conclusions about the adequacy of the PSQ in measuring dimensions of pay satisfaction.

When evaluating past research on the PSQ, it is clear that the dimensions of pay satisfaction are not independent, and in fact several are highly related. However, this does not necessarily undermine the validity of the PSQ. Dimensions of compensation are not independent, so one should not expect dimensions of pay satisfaction to be independent. For example, since pay raises subsequently affect pay level, individuals satisfied with their pay raises are likely in turn to be more satisfied with their pay level. The real issue seems to be, Are the dimensions conceptually and empirically separable? That is, Are they capable of being distinguished from one another? Although the dimensions of the PSQ seem to measure conceptually different domains, it must also be ascertained, in as rigorous a manner as possible, whether the measures are sufficiently distinct to merit consideration as measurements of separate constructs. This is critical because measures of seemingly different constructs often are not empirically distinct (Schwab, 1980). Since the discriminant validity of the dimensions of the PSQ goes to the very heart of its usefulness, and since past research has not adequately resolved this issue, a study investigating the discriminability of the dimensions would contribute to the pay satisfaction literature.

Relatedly, while there have been a number of studies investigating the determinants of pay satisfaction, Milkovich and Newman (1990) have pointed out that despite past research, considerable ambiguity remains regarding the antecedents of pay satisfaction. A potential path out of this confusion lies in considering pay satisfaction as a multidimensional construct. Because the factors that cause pay satisfaction may differ across the various dimensions of pay satisfaction, inconsistent results obtained with respect to the determinants of pay satisfaction may be due to unidimensional conceptualizations and the measurement of pay satisfaction. On the basis of this rationale, H. Heneman (1985), and more recently Miceli and Lane (1991), have issued calls for research investigating the determinants of pay satisfaction dimensions. Such work may have considerable practical appeal, in that the steps an organization takes to remedy pay dissatisfaction likely depend on the source of the dissatisfaction.

Thus, the present study seeks to address a number of research needs regarding the PSQ. First, given that a reasonable basis exists for hypothesizing the dimensions of pay satisfaction, and since many of the 
assumptions of exploratory factor analysis are tenuous (Long, 1983), confirmatory rather than exploratory factor analysis should be used since with confirmatory factor analysis the hypothesized factor structure appropriately drives the analysis rather than the analysis being "data driven" (Bobko, 1990). Investigations of the dimensionality of the PSQ have largely relied on exploratory factor analysis (for an exception see the brief report by Mulvey, Miceli, \& Near, 1992). Interpretation of exploratory factor analysis results is limited by the subjectivity in which factor loadings, cross-factor loadings, and factor independence are assessed. Perhaps as a result, these investigations have yielded conflicting results regarding the dimensionality of the PSQ. For example, the recent works of Ash, Dreher, and Bretz (1987), Carraher (1991), R. Heneman, Greenberger, and Strasser (1988), Orpen and Bonnici (1987), and Scarpello, Huber, and Vandenberg (1988) have reached somewhat conflicting conclusions about the dimensionality of pay satisfaction. A confirmatory approach that is theory-driven should help reduce this ambiguity.

Second, and perhaps more important, there have been no direct investigations of the discriminant validity of the PSQ. Covariance structure modeling is well-suited for investigations of discriminant validity (Long, 1983), including comparing the fit of alternative models and examining patterns of correlations between factors with hypothesized predictors, neither of which has been conducted to date with respect to the PSQ. While a number of studies have investigated predictors of individual dimensions of pay satisfaction (e.g., Dreher, Ash, \& Bretz, 1988; Folger \& Konovsky, 1989; R. Heneman et al., 1988; Miceli, Jung, Near, \& Greenberger, 1991; Sweeney, McFarlin, \& Inderrieden, 1990), these studies have not explicitly compared the relative effects of predictors on the different dimensions of pay satisfaction by formally testing the degree to which various predictors exert significantly different effects on each dimension of pay satisfaction. This is a necessary step in determining the degree to which the dimensions of the PSQ are actually distinct. While some researchers have subjectively compared the relative effects of various antecedents on the dimensions of pay satisfaction (e.g., R. Heneman et al., 1988; Miceli et al., 1991), these relative effects were not directly tested for significance. As a result, while the PSQ continues to be used and researched, no rigorous tests of its validity exist.

\section{Hypotheses and Model of Pay Satisfaction}

In evaluating the validity of the dimensions of the PSQ, the concepts of convergent validity (the degree to which responses from individual measurements of the same construct share covariance) and discriminant 
validity (the degree to which the constructs are sufficiently distinct) are relevant (Schwab, 1980). It is expected that the dimensions of the PSQ will display both convergent and discriminant validity. Specifically, items from the PSQ should load on their hypothesized dimensions, and the four dimensions of pay satisfaction should be empirically distinguishable. This follows from the dimensions hypothesized by $\mathrm{H}$. Heneman and Schwab (1985). As pointed out by H. Heneman (1985) and H. Heneman and Schwab (1985), each dimension reflects a relatively distinct (although perhaps related) aspect of pay. For example, the criteria used to establish benefit coverage of employees is not likely to strongly depend on how pay structures are established, the magnitude of pay raises given, and so on. Thus,

Hypothesis la: Items from the PSQ will load on their hypothesized dimensions.

Hypothesis $1 b$ : The dimensions of the PSQ will be empirically distinct.

In addition to establishing discriminant validity by showing that the constructs are empirically separable, another means of demonstrating discriminant validity is to compare the correlations that the constructs (i.e., the PSQ dimensions) have with a series of predictors (Gerhart \& Judge, 1991; Schwab, 1980). If the purportedly different constructs display similar patterns of correlations with a number of predictors, the utility of distinguishing between the constructs is called into question. For example, if the variables that predict one dimension of pay satisfaction similarly predict the other dimensions, there would be a strong basis for doubting the discriminant validity of the dimensions. Since each dimension of the PSQ represents a conceptually distinct aspect of compensation (H. Heneman, 1985), it is expected that the influences on each of these dimensions will be significantly different in terms of the magnitude of their effects. Thus,

Hypothesis 2: Each dimension of the PSQ will display a significantly different pattern of relationships with its hypothesized influences.

In order to determine if a number of variables predict dimensions of pay satisfaction as hypothesized below, an overall model of pay satisfaction was hypothesized. This also has implications for the validity of the PSQ dimensions. Discussion of links within this model is organized around each dimension of pay satisfaction. Justification of each dimension's predictors follows; the predictors for each PSQ dimension are grouped together as an overall hypothesis. 


\section{Pay Level Satisfaction}

The level of compensation is one of the more important job attributes to individuals (Jurgensen, 1978). Not surprisingly, salary or wages as measures of pay level consistently have been shown to predict pay satisfaction among a number of different occupational groups (Berger \& Schwab, 1980; Dreher, 1980; Dreher et al., 1988; Futrell, 1978; Hemmasi, Graf, \& Lust, 1992; Lawler, 1971; Motowidlo, 1982; Ronan \& Organt, 1973; Schwab \& Wallace, 1974). Of the four dimensions of pay satisfaction, one would expect that pay level would most strongly predict pay level satisfaction (Miceli \& Lane, 1991). Thus,

Hypothesis $3 a$ : Salary level will positively predict pay level satisfaction.

The importance of external comparisons in shaping judgments of pay satisfaction has been emphasized by a number of authors (Dyer \& Theriault, 1976; Gerhart \& Milkovich, 1992; Lawler, 1971; Miceli \& Lane, 1991; Rice, Phillips, \& McFarlin, 1990; Taylor \& Vest, 1992). As pointed out by Scholl, Cooper, and McKenna (1987), equity theory would predict that a major influence on pay level satisfaction is a comparison of one's pay relative to that of referent others. Since these comparisons probably most often involve the individual's level of pay relative to others, external comparisons should most strongly influence pay level satisfaction. Thus,

Hypothesis $3 b$ : Pay relative to others doing similar work in other companies will positively predict pay level satisfaction.

\section{Pay Raise Satisfaction}

Individuals who historically have received higher raises in the past should be more satisfied with their raises (Dyer \& Theriault, 1976). Since pay raises contribute to pay level, pay raise history may have an indirect effect on pay level satisfaction, but it is expected that the most proximal influence is on pay raise satisfaction. In fact, Folger and Konovsky (1989) reported that pay raise amount and pay raise satisfaction were significantly positively related $(r=.33 ; p<.01)$. Similarly, R. Heneman et al. (1988) reported a significant correlation between salary increase and pay raise satisfaction $(r=.23 ; p<.01)$, while salary increase did not significantly correlate with any other PSQ dimension. Thus,

Hypothesis 4a: Pay raise history will positively predict pay raise satisfaction.

Dyer and Theriault (1976) hypothesized that the perceived accuracy of performance assessment positively influences pay satisfaction. Miceli 
et al. (1991) hypothesized that one of the principal components of the fairness of a pay system is the degree to which formal performance appraisal standards are followed. Since merit pay is based on performance ratings, these attitudes should be influential in judgments of pay raise satisfaction. As pointed out by Folger and Konovsky (1989), psychologically one would expect attitudes about the performance appraisal process to be influential in forming judgments of pay raise satisfaction because employees perceive inadequate performance appraisals to be procedurally unfair with respect to the process of obtaining pay increases. Thus,

Hypothesis 4b: Attitudes about the performance appraisal process will positively predict pay raise satisfaction.

Dyer and Theriault (1976) hypothesized that perceived appropriateness of pay criteria influences pay satisfaction. It is expected that in a merit pay context employees who perceive pay increases to be based on criteria other than performance are also less likely to see the criteria as appropriate. Therefore, lower satisfaction with pay raises should result. Support for this hypothesis comes from Folger and Konovsky (1989), who found that performance-to-pay perceptions were significantly related to pay raise satisfaction. R. Heneman et al. (1988) found that payfor-performance perceptions were more highly correlated with pay raise satisfaction than with the other dimensions of the PSQ. Thus,

Hypothesis 4c: The perceived contingency between performance and pay will positively predict pay raise satisfaction.

The time interval over which merit raises are given is expected to be influential in judgments of pay raise satisfaction. Employees who are eligible for pay increases over longer time intervals are receiving lower effective annual increases (e.g., an employee who receives a 5\% raise every 8 months receives $50 \%$ higher real pay increases than an employee receiving the same raise over 12-month intervals). Thus,

Hypothesis 4d: The length of the interval over which employees are eligible for a merit raise will negatively predict pay raise satisfaction.

Finally, in a merit pay context the employee's supervisor often directly or indirectly controls pay raises. Thus, since most employees feel they are good performers, they expect their managers to deliver adequate pay raises to them (Miceli et al., 1991). However, managers who have little influence over pay increases have a limited ability to do this (Miceli \& Lane, 1991). Employee dissatisfaction with pay raises is a likely result. Thus, 


\section{$4 B$}

TIMOTHY A. JUDGE

Hypothesis 4e: Manager influence over pay will positively predict pay raise satisfaction.

\section{Structure/Administration Satisfaction}

Dyer and Theriault (1976) hypothesized that perceived understanding of pay criteria positively influences pay satisfaction. Since understanding of pay criteria pertains to how pay policies are communicated and administered, one would expect that the more individuals understand a pay system, the higher structure/administration satisfaction they will report. Thus,

Hypothesis 5a: Understanding of pay criteria will positively predict pay raise satisfaction.

As hypothesized by Miceli and Lane (1991), perceived managerial influence over pay should affect satisfaction with the way the pay system is administered; those who believe that their manager has little influence over their pay should be less satisfied with the administration of their pay. Therefore, in addition to influencing pay raise satisfaction, it is reasonable to expect that the ability of the supervisor to control the allocation of pay will affect satisfaction with the administration of pay. Thus,

Hypothesis $5 b$ : Manager influence over pay will positively predict structure/administration satisfaction.

H. Heneman (1985) argued that attitudes about the performance appraisal process were often related to pay system administration. In fact, Dyer and Theriault (1976) found that such attitudes influenced pay satisfaction, and Miceli et al. (1991) found that adherence to formal performance appraisal standards significantly influenced perceived fairness of the pay system for managers and executives. Thus,

Hypothesis 5c: Attitudes about the performance appraisal process will positively predict structure/administration satisfaction.

\section{Benefit Satisfaction}

Two of the principal influences on benefit satisfaction are benefit coverage and employee cost (Dreher et al., 1988). Since benefit coverage within an organization is often constant across employees (i.e., benefits are offered to all employees regardless of their position in the organization), when one is concerned with employees in a single organization, 
it may be fruitful to investigate factors that differ between individuals (Gerhart \& Milkovich, 1992; Miceli \& Lane, 1991). Thus, in situations where employee benefit coverage is fixed, one would expect that individual differences that affect the relative use or cost of benefits would be most predictive of benefit satisfaction. A relevant demographic influence may be age. In fact, Miceli and Lane argued that age may negatively influence benefit satisfaction. The use of medical benefits, the most expensive benefits to employers and often to employees (Milkovich \& Newman, 1990), increases with age (Taubman \& Rosen, 1982). This often results in greater expense to employees because under most plans copayments and deductibles increase with benefit usage. Since older employees may be particularly sensitive to out-of-pocket benefit expenses (Barringer, Milkovich, \& Mitchell, 1991), they are expected to be less satisfied with their benefits. Thus,

Hypothesis 6a: Age will negatively predict benefit satisfaction.

Miceli and Lane (1991) argued that as inputs into the benefit system (co-payment, deductibles, etc.) increase relative to benefit outcomes, satisfaction with benefits should decrease. Since in the organization under study co-payments into the health insurance fund are based on salary grade, yet coverage is constant across salary grades, it is expected that the higher the salary grade an employee is in, the lower the level of benefit satisfaction the employee will report. Thus,

Hypothesis $6 b$ : Salary grade level will negatively predict benefit satisfaction.

\section{Method}

\section{Setting and Subjects}

The setting for this research was a strategic business unit (SBU) from a Fortune 100 company that is involved in the production and marketing of high technology goods and services. The SBU is organized into five divisions, which are geographically dispersed from the midAtlantic coast area to New England to California. Employees were surveyed from all five divisions of the SBU. In the SBU, pay increases were awarded through a variable-time merit pay program, which allocated pay increases as a function of the total merit increase pool, the employee's current performance rating, and the employee's position in the salary grade. Employees positioned high in their salary grade received lower 
increases, and were eligible for increases less often, than employees positioned low in their salary grade. Benefit coverage was constant across all employees. All employees were eligible for the following benefits: paid vacation and holidays; dental, medical, and disability insurance; profit sharing for retirement; employee stock ownership; tuition reimbursement; and tax deferrals for child care.

Subjects consisted of four principal employee groupings: managers (28\%), professional/technical employees ( $42 \%)$, sales representatives (10\%), and nonexempt employees (20\%). Education level of the respondents was as follows: high school diploma or associates degree $(34 \%)$, undergraduate degree (47\%), master's degree $(17 \%)$, and doctoral degree $(2 \%)$. The average annual salary of the employees was $\$ 55,755$ (SD $=\$ 22,398$ ), within a range from $\$ 17,576$ to $\$ 145,750$. The average respondent had received roughly 1 promotion in the last 3 years. Respondents were from 18 to 64 years old, with an average age of 40.7 years. Organizational tenure ranged from newly employed to 32 years; average tenure with the organization was 10.6 years. Sixty-two percent of employees were male, and $26 \%$ were members of minority groups. The average employee had been in their present salary grade for about 29 months, had averaged a $4.6 \%$ merit pay raise over the past 3 years, and was eligible for pay increases approximately every 14 months.

Seven hundred eighty-two employees worked in the SBU. Six hundred sixty-four individuals returned surveys $(85 \%)$. Six hundred thirty individuals completed usable surveys, representing a usable response rate of $81 \%$. Using data obtained from the human resource information system, no significant differences were found between respondents and nonrespondents with respect to salary, pay raise history, age, salary grade, or interval between pay raise eligibility. Thus, the sample was representative of the larger population of employees.

\section{Procedure}

Prior to survey administration, the SBU president and vice-president of human resources announced that an employee attitude survey was to be conducted and asked for voluntary participation in the process. Survey administration was coordinated by a human resource manager in the SBU. Secretaries in each division maintained a roster of participants, and were responsible for follow-up. The actual survey contained a letter and informed consent form from the survey administrator and the author informing employees of the purpose and intended use of the survey. Envelopes addressed to the author were provided with the surveys. Upon completing the survey, respondents were instructed to place the survey in the envelope and return it in the mail. Feedback regarding the 
results of the survey was promised and subsequently delivered. Before completing the survey, employees were asked to provide their employee identification number. Confidentiality of the results was assured, meaning that no individual in the organization (including the survey administrator) would see responses that could be linked to an individual employee's name. Prior to data analysis, survey responses were matched with archival data using the employees' identification numbers.

\section{Measures}

Pay satisfaction. Pay satisfaction was measured by the 18 -item version of the Pay Satisfaction Questionnaire (H. Heneman \& Schwab, 1985). Respondents indicated their satisfaction with 18 statements describing their compensation. Satisfaction with the statements was expressed on a $1=$ "very dissatisfied" to 5 = "very satisfied" scale. Items corresponding to each subscale were summed and then divided by the number of items in each subscale. The coefficient alpha reliability estimate for the overall scale was .89 .

Hypothesized predictors from survey. Understanding of the pay system was measured by soliciting the respondents' reaction to the following statement, "I understand the criteria my organization uses to administer pay." Perceived managerial influence over pay was measured by respondent reactions to the following statement, "My manager has a large influence over salary decisions." Perceived contingency between performance and pay was measured by asking the respondent to react to the following statement, "If I improve my performance, I will receive an appropriate increase in pay rewards and other financial recognition." Respondents indicated their agreement with these statements on a $1=$ "strongly disagree" to $5=$ "strongly agree" scale. Perceived pay relative to others performing similar work in other organizations was measured by asking the respondants to compare their pay to the pay of those who work in similar jobs in other organizations $(1=$ "our organization's pay is much lower" to $5=$ "our organization's pay is much higher"). Finally, employee attitudes about the organization's performance appraisal system were measured by a 7-item questionnaire which consisted of statements about the accuracy, understanding, and developmental quality of the performance appraisal process (e.g., "I clearly understand my performance objectives," "I participate in setting my performance objectives"). Respondents indicated their agreement with these questions on a $1=$ "strongly disagree" to $5=$ "strongly agree" scale. The coefficient alpha reliability estimate for this scale was .73 .

Archival information. Salary, age, salary grade, interval between pay raise eligibility, and past raise history (average of past three merit raises) 
were collected from data contained in the organization's human resource information system.

\section{LISREL Analyses}

In order to test the degree to which items from the PSQ load on their hypothesized dimensions and the degree to which the dimensions are empirically separable (Hypothesis 1 ), confirmatory factor analysis was conducted using LISREL 7 (Jöreskog \& Sörbom, 1989). Confirmatory factor analysis is particularly well suited to investigate construct validity, since it allows direct investigation of the degree to which specific items jointly load on their hypothesized constructs (i.e., convergent validity), and the degree to which purportedly different constructs are capable of being distinguished from one another (i.e., discriminant validity; Bollen, 1989; Long, 1983). Convergent validity of the PSQ (Hypothesis 1a) can be inferred from the loadings of the items on the four dimensions. The first step in investigating the discriminant validity of the PSQ dimensions is to establish the degree to which the dimensions are distinct (Hypothesis 1b). This can be accomplished by comparing the fit of the hypothesized model with a model consisting of one general pay satisfaction construct. If the measures of the dimensions do not have adequate discriminant validity, the fit of a single-factor model will not be significantly worse than the fit of the hypothesized four-factor model. In such a case, a single-factor model would adequately describe the data, and the hypothesis of the multidimensional nature of pay satisfaction would be rejected.

A second step in establishing discriminant validity is to investigate if measures of purportedly different constructs display different patterns of correlations with their predictors. Consistent with Brooke, Russell, and Price (1988) and Mathieu and Farr (1991), this was performed by testing if the hypothesized predictors of each dimension of pay satisfaction were significantly different from one another (Hypothesis 2). As one example, if salary level exerts a similar effect on all four dimensions of pay satisfaction, it provides one piece of evidence suggesting that the dimensions are not particularly distinct. To the extent this is true with all or most of the predictors, the actual discreteness of the dimensions is called into question.

Finally, the hypothesized model of pay satisfaction was tested using LISREL. Significance tests of the specific coefficient estimates will provide tests of Hypotheses $3 \mathrm{a}$ through $6 \mathrm{~b}$ and will provide further evidence regarding the distinction between the PSQ dimensions. 


\section{Results}

Table 1 presents the correlations and scale reliabilities among the four PSQ dimensions for the total sample, and for the four employee groups represented in the SBU. The intercorrelations among the dimensions are consistent with past research (Scarpello et al., 1988). Specifically, the benefits dimension correlated considerably lower with the other three dimensions than those dimensions did with each other. The pay raise scale correlated .62 with the pay level and structure/administration scales, and the structure/administration scale correlated .52 with the pay level scale. Although these correlations are moderately high, they are far from unity, even when corrected for unreliability. Finally, the scale reliabilities for the PSQ dimensions were comparable to those found in past research.

Table 1 also shows the correlations among the PSQ dimensions for the four employee groups. Overall, the pattern of correlations is similar for the different groups of employees. The average absolute difference in correlations between the four dimensions across all employee groups was .09. The largest differences across the employee groups were the correlations between the pay level scale and the other dimensions. This may be due to the fact that the actual level of pay differs widely across the groups. Finally, the reliabilities of the dimensions are relatively stable across the employee groupings.

\section{Test of Hypothesis 1}

Table 2 provides the parameter estimates (factor loadings) of the measures on their respective constructs for the hypothesized four-dimension pay satisfaction model. All factor loadings for the four dimensions of pay satisfaction are relatively strong (average loading $=.727$ ) and highly significant $(p<.01)$. The factor loadings were relatively stable across the various employee groups. The absolute average difference in factor loadings across the four employee groups was $.076(S D=.040)$, with a range from .03 to .16 . By usual conventions, the fit statistics from the confirmatory factor analysis indicate that the hypothesized measurement model provides an adequate fit to the data $\left(\chi^{2}=490.79\right.$ with 129 degrees of freedom, $p<.01 ; \chi^{2} / d f=3.80$; goodness-of-fit index $=.92$; adjusted goodness-of-fit index $=.89$; root-mean-square residual $=.05$; $R^{2}=.99$ ). Thus, the measurement model results support Hypothesis 1a.

As indicated earlier, a means of testing the discriminant validity of the PSQ dimensions is to compare the fit of a single-factor model to the fit of the hypothesized model (Hypothesis $1 \mathrm{~b}$ ). The single-factor model provided a very poor fit to the data $\left(\chi^{2}=2,809.58\right.$ with 135 degrees of 
TIMOTHY A. JUDGE

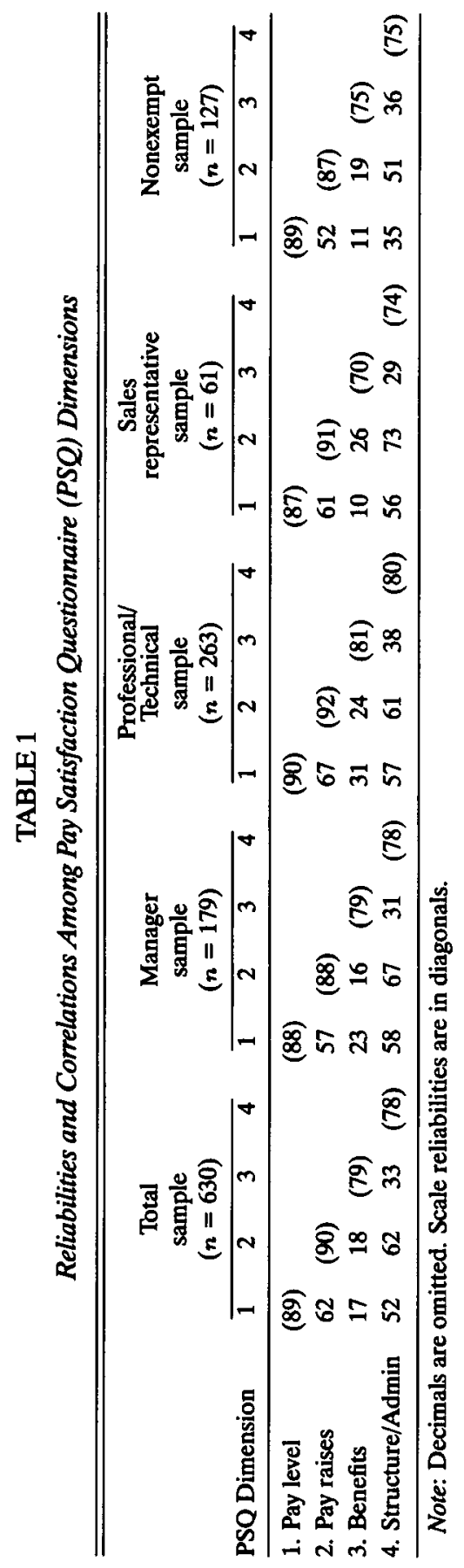


TABLE 2

LISREL Estimates of Pay Satisfaction Questionnaire Factor Loadings

\begin{tabular}{|c|c|c|c|c|}
\hline Item & Level & Benefits & Raise & $\begin{array}{c}\text { Structure/ } \\
\text { Administration }\end{array}$ \\
\hline My take home pay & .89 & & & \\
\hline My current salary & .92 & & & \\
\hline My overall level of pay & .90 & & & \\
\hline Size of my current salary & .59 & & & \\
\hline My benefit package & & .85 & & \\
\hline Amount the company pays toward my benefits & & .80 & & \\
\hline The value of my benefits & & .91 & & \\
\hline The number of benefits I receive & & .79 & & \\
\hline My most recent increase & & & .73 & \\
\hline Influence my supervisor has over my pay & & & .65 & \\
\hline $\begin{array}{l}\text { The raises I have typically received in } \\
\text { the past }\end{array}$ & & & .66 & \\
\hline How my raises are determined & & & .74 & \\
\hline The company's pay structure & & & & .75 \\
\hline $\begin{array}{l}\text { Information the company gives about pay issues } \\
\text { of concern to me }\end{array}$ & & & & .56 \\
\hline Pay of other jobs in the company & & & & .45 \\
\hline Consistency of the company's pay policies & & & & .72 \\
\hline Differences in pay among jobs in the company & & & & .60 \\
\hline How the company administers pay & & & & .59 \\
\hline
\end{tabular}

Note: All loadings are significant at the .01 level; $N=630$.

freedom, $p<.01)$. This fit was significantly worse than the hypothesized model (increase in $\chi^{2}=2,318.79$ with 6 degrees of freedom, $p<.01$ ). Even forming the most highly related dimensions, pay raise satisfaction with structure/administraion satisfaction and pay raise satisfaction with pay level satisfaction, into one resulted in a significant decrease in fit (increase in $\chi^{2}=140.48$ with 3 degrees of freedom, $p<.01$, and increase in $\chi^{2}=359.61$ with 3 degrees of freedom, $p<.01$, respectively). Also, the three-factor solution hypothesized by Ash et al. (1987) provided a significantly worse fit to the data than the hypothesized four-factor solution (increase in $\chi^{2}=158.67$ with 3 degrees of freedom, $p<.01$ ). In sum, items from the PSQ loaded on their hypothesized dimensions; some dimensions of the PSQ were highly correlated but confirmatory tests suggest that even the most highly related dimensions are distinct. Thus, Hypothesis 1 was supported by the results.

\section{Test of Hypothesis 2}

The correlations between the hypothesized predictors and the dimensions of pay satisfaction are presented in Table 3. The table indicates that the pattern of correlations is as hypothesized. Each predictor correlated most highly with the dimension it was hypothesized to predict. In 
TABLE 3

Correlations Between Pay Satisfaction Questionnaire Dimensions and Hypothesized Predictors

\begin{tabular}{lcccc}
\hline & \multicolumn{4}{c}{ PSQ Dimension } \\
\cline { 2 - 5 } \multicolumn{1}{c}{ Hypothesized predictor } & Level & Benefits & Raise & $\begin{array}{c}\text { Structure } \\
\text { Administration }\end{array}$ \\
\hline Salary & .30 & -.29 & .09 & .02 \\
Pay raise history & .04 & .08 & .25 & .10 \\
Understanding of pay system & .18 & .06 & .23 & .30 \\
Salary grade & .13 & -.20 & .10 & .10 \\
Age & .14 & -.20 & -.01 & .01 \\
Performance appraisal attitudes & .30 & .17 & .54 & .42 \\
Performance-pay contingency & .35 & .07 & .52 & .44 \\
Manager influence over pay & .03 & .00 & .18 & .17 \\
Pay raise interval & .07 & -.12 & -.17 & -.08 \\
Pay relative to others doing & & & & \\
$\quad$ similar work in other companies & .44 & .18 & .24 & .29 \\
\hline
\end{tabular}

Note: Correlations greater than .08 are significant at the .01 level.

order to investigate if this pattern of correlations differed significantly across the PSQ dimensions (Hypothesis 2), two models were estimated for each of the hypothesized predictors. One model allowed the correlations of each hypothesized predictor with each of the four dimensions of pay satisfaction to be freely estimated. The other model constrained the correlations of the hypothesized predictor with each dimension to be equal. For example, one model allowed the correlations between salary and the four PSQ dimensions to be freely estimated. The other model constrained the correlations between salary and the four PSQ dimensions to be equal. If the fit of these two models is not significantly different, then that variable exerts a similar influence on all dimensions. In each case, equating the correlations between the four dimensions and each hypothesized predictor resulted in a significant decrease in fit $(p<$ $.01)$. This suggests that the variables do exhibit different patterns of correlations with a number of predictors, and these patterns generally follow expectations. Consistent with Gerhart and Judge (1991), the average absolute difference in the correlations across the PSQ dimensions was computed. The average absolute difference was .17, which was significant $(p<.01)$. Thus, Hypothesis 2 was supported by the results. Overall, this evidence suggests the dimensions of the PSQ display discriminant validity.

In addition to supporting the discriminant validity of the PSQ, the results in Table 3 also are relevant with respect to Hypotheses 3-6. Specifically, the correlations in Table 3 indicate that each correlate was significantly related to its hypothesized dimension of pay satisfaction. Furthermore, each variable correlated most highly with its hypothesized PSQ 
dimension. For example, the correlation between pay raise history and pay raise satisfaction was higher than the correlation between pay raise history and the other three PSQ dimensions. The fact that this pattern held for all hypothesized influences provides supportive evidence for $\mathrm{Hy}-$ potheses 3-6. A more rigorous multivariate test of these hypotheses is undertaken in the next section.

\section{Tests of Hypotheses 3-6}

In order to test Hypotheses 3-6, an overall model of pay satisfaction was tested using LISREL 7 (Jöreskog \& Sörbom, 1989). Results from this estimation revealed that the overall fit of the model was acceptable $\left(\chi^{2}=928.20\right.$ with 313 degrees of freedom, $p<.01 ; \chi^{2} / d f=$ 2.97; goodness-of-fit index $=.90$; adjusted goodness-of-fit index $=.87$; root-mean-square residual $=.09 ; R^{2}=.65$ ). The specific links within the model are displayed in Figure 1. As the figure illustrates, all links were supported. Specifically, those who earned higher salaries and those who perceived their pay to be high relative to others doing similar work in other companies were significantly more satisfied with their pay level. Thus, Hypotheses $3 \mathrm{a}$ and $3 \mathrm{~b}$ were supported by the results. Employees who had a history of higher pay raises, had positive attitudes about the performance appraisal process, perceived a high contingency between their performance and their pay, had received pay increases on a shorter interval, and those who felt that their manager had an influence on their pay were significantly more satisfied with their pay raises. Thus, Hypotheses $4 \mathrm{a}-4 \mathrm{e}$ received support from the results. Employees who understood their pay system, who perceived that their supervisor had influence over their pay, and who had positive attitudes about the performance appraisal process were significantly more satisfied with the structure and administration of their pay. This provides support for Hypotheses 5a-5c. Finally, older employees and those in higher salary grades were significantly less satisfied with their benefits, supporting Hypotheses $6 \mathrm{a}$ and $6 \mathrm{~b}$.

In demonstrating differential prediction, it is important to demonstrate that variables that predict one dimension of pay satisfaction do not predict the other dimensions of pay satisfaction. Modification indices provided by the LISREL algorithm are useful here because a modification index is an estimate of the improvement in chi-square that would be obtained from adding a specific link in the model (Jöreskog \& Sörbom, 1989). Of the 28 possible additional links in the model in Figure 1, only 4 were statistically significant (due to the large number of additional paths considered, alpha inflation was controlled using the Bonferroni procedure; Hays, 1980). These 4 significant links were from performance-pay 


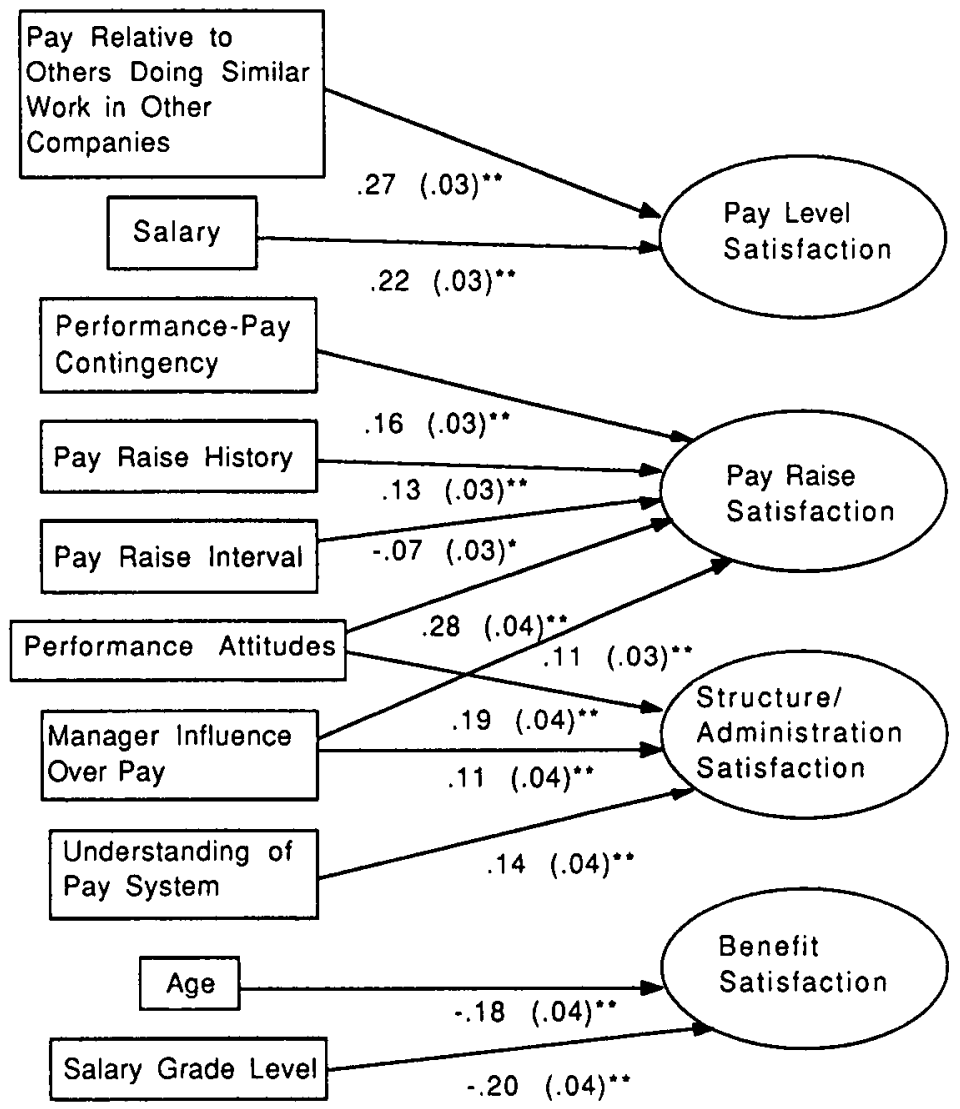

Note: ${ }^{*} p<.05 ;{ }^{* *} p<.01$. Standard errors are in parentheses.

\section{Figure 1: LISREL Estimates of Hypothesized Model}

contingency to pay level satisfaction and to structure/administration satisfaction, and from attitudes about the performance appraisal system to pay level satisfaction and to benefit satisfaction. However, in all except one case, when each of these links was added to the model it was significantly lower in magnitude than the relevant hypothesized links displayed in Figure 1 (the only exception was that the link from attitudes about the performance appraisal system to pay level satisfaction was not significantly lower than the link from attitudes about the performance appraisal system to structure/administration satisfaction). Thus, only 4 of 28 additional links were significantly different from zero, and of the 4 
that were significant only 1 was not significantly weaker than the hypothesized links. Overall, this provides support for the discriminant validity analysis reported earlier, and for differential prediction of the dimensions of the PSQ.

\section{Discussion}

The present study provides supportive evidence for the validity of the Pay Satisfaction Questionnaire. The items from the PSQ loaded highly on their hypothesized dimensions, and the overall fit also supported the hypothesized model. Furthermore, the factor loadings were similar across job classifications. More importantly, several empirical tests supported the discriminant validity of the PSQ. First, the dimensions of the PSQ were empirically separable; combining even the most highly related dimensions significantly reduced the fit of the model. Also, a three-factor solution was outperformed by the hypothesized four-factor solution. Second, the dimensions displayed differing patterns of correlations with hypothesized predictors; the combination of convergent and discriminant validity evidence suggests that the dimensions of the PSQ are valid. This evidence indicates that combining the dimensions loses important information about the potential causes of, and remedies to, pay dissatisfaction.

The hypothesized model of pay satisfaction received strong support from the results. The hypothesized predictors of pay satisfaction, although not inclusive, were derived from a review of past research. Support for the set of hypothesized predictors provides further indication that the dimensions of the PSQ are valid; the variables exerted influences on the dimensions of pay satisfaction consistent with what was hypothesized. The model also was robust in that the hypothesized predictors generally were significantly stronger in magnitude than the alternative links.

The influence of some of the variables on the dimensions of pay satisfaction was predictable. For example, it would have been surprising if salary did not influence pay level satisfaction. The same holds true for pay relative to others doing similar work in other companies with respect to pay level satisfaction, and pay raise history and pay raise interval with respect to pay raise satisfaction. Nevertheless, substantiation of these links does increase confidence in the validity of the PSQ, particularly given the fact that these variables exerted significant effects on the hypothesized dimensions, but not on any other dimension of the PSQ. This was true for most of the other links in the model as well. 
A number of attitudinal variables influenced the dimensions of pay satisfaction. Specifically, performance-pay contingency, manager influence over pay, and attitudes about the performance appraisal system significantly predicted pay raise satisfaction; the latter two variables also predicted structure/administration satisfaction along with understanding of the pay system. Although there is some reason to place limited weight on the substantive interpretation of these relationships, the results nonetheless suggest that employee perceptions and attitudes significantly relate to the dimensions of pay satisfaction, and overall these variables differentially predicted the PSQ dimensions consistent with the hypotheses. This responds to R. Heneman et al.'s (1988) request for more research investigating the role of perceived characteristics of pay systems on the dimensions of pay satisfaction.

Results of the alternative model testing, which consisted of adding links from the variables to the dimensions of pay satisfaction (e.g., from salary to benefit satisfaction and to structure/administration satisfaction, from age to pay level satisfaction, to raise satisfaction, and to structure/administration satisfaction, etc.) yielded generally positive results. Only 4 of the 28 added linkages were significantly different from zero. Furthermore, only 1 of these 4 links was not significantly weaker than the hypothesized link. For example, the modification index suggested that adding a link from attitudes about the performance appraisal system to benefit satisfaction would result in a significant increase in fit, and in fact when the link was added the coefficient estimate was significant. However, the magnitude of this coefficient (.15) was significantly weaker than the hypothesized link from attitudes about the performance appraisal system to either pay raise satisfaction or to structure/administration satisfaction. Thus, only 1 of the 28 additional links was as strong as the hypothesized links.

On the other hand, it is not clear why some of the 4 links were significant. For example, it is difficult to determine why performance appraisal attitudes significantly predicted benefit satisfaction. Conversely, the effect of performance-pay contingency on structure/administration satisfaction is easier to understand, particularly in light of the fact that R. Heneman et al. (1988) also found such a relationship. In sum, the results do support differential prediction, although the results are not totally unequivocal. It would be useful for future research to consider these issues further. 


\section{Limitations, Contributions, and Future Research}

This study has several limitations that need to be noted. First, while the organization under study was heterogeneous with respect to demography, job classifications of its employees, and geographical region, it is still only one organization. This raises the possibility that the findings are firm specific. Although there is no particular reason to believe that the results obtained are unique to the organization, this obviously is an empirical question that could be answered with further research.

A second limitation is that a number of predictors were measured by single items (managerial influence over pay, understanding of pay system, contingency between pay and performance, pay relative to others). Although Scarpello and Campbell (1983) demonstrated that singleitem measures are not unreliable, and may be as valid as multiple-item measures, single-item measures may be deficient and thus fail to empirically capture the conceptual domain of the construct. Thus, the fact that several single-item measures were used in this study is a limitation that needs to be acknowledged. Also, although many relationships tested in the study are not subject to mono-method bias, several are vulnerable to this criticism. This may be particularly problematic in interpreting the effect of manager influence over pay on pay raise satisfaction, since the measurement of the predictor is similar to the content of an item in the PSQ (see Table 2), causing this relationship to suffer from definitional dependency. In light of the potential problems created by common method variance, some of the relationships in the model should be substantively interpreted with some degree of caution.

Finally, the methods used to establish the validity of the PSQ dimensions, although sophisticated, are nonetheless imperfect. LISREL is well-suited to investigate construct validity (Long, 1983), but one should not interpret the results as proof of validity (Gerhart \& Judge, 1991). Like any other method of analysis, restrictive assumptions must be met before causal inferences can be made (James, Mulaik, \& Brett, 1982). One assumption is clear causal ordering among the variables, which is often questionable when analyzing cross-sectional data. For example, while it seems logical that performance to pay contingencies should predict pay raise satisfaction, it is possible that such a perception is influenced by pay raise satisfaction. The failure to meet all assumptions necessary for causal inference suggests that the results should be interpreted with some degree of caution pending further confirmatory evidence.

Despite these limitations, the present study adds to the current state of knowledge of pay satisfaction. Most fundamentally, this study has provided the first direct test of the discriminant validity of the dimensions of the PSQ. While some research has investigated influences on individual 
dimensions of pay satisfaction (Dreher et al., 1988; Folger \& Konovsky, 1989; Miceli et al., 1991), these studies did not statistically test the significance of the differences in the relative effects of antecedents on the four dimensions. For example, Dreher et al. uncovered influences on benefit satisfaction, Folger \& Konovsky investigated several determinants of pay raise satisfaction, and Miceli et al. found a number of factors influencing pay-system fairness. However, none of these studies directly tested for significant differences in the relative effects. R. Heneman et al. (1988) did report more information in this regard, but did not explicitly test the degree of differential prediction, or directly test the discriminant validity of the dimensions of the PSQ. Thus, the present study contributes to the pay satisfaction literature by demonstrating that the dimensions of pay satisfaction as represented by the PSQ are distinct, and that the influences on pay satisfaction consistently followed expectations. No previous research has formally tested the independence of the PSQ dimensions, or directly compared the effect of a series of hypothesized antecedents on the dimensions of pay satisfaction by statistically testing the degree of differential prediction among the antecedent variables.

\section{Implications for Practice}

The results of this study provide a number of implications for practice. The results suggest that organizations concerned about the pay satisfaction of their employees may be well-advised to consider the dimensionality of pay satisfaction. Reliance on measures of overall pay satisfaction may provide limited information about the causes of pay dissatisfaction, and may mask potential problems. For example, high employee satisfaction with some dimensions of pay satisfaction may offset strong dissatisfaction with other dimensions. The results obtained from the organization under study may provide a case in point. The mean level of benefit satisfaction $(M=3.62 ; S D=0.76)$ was significantly higher than the average level of pay raise satisfaction $(M=2.78 ; S D=0.81)$. If one only considered overall pay satisfaction, these two would average out and obscure the fact that pay raise satisfaction is not viewed favorably by employees relative to the other dimensions of pay satisfaction. Since it is possible that benefit satisfaction is generally higher than pay raise satisfaction across organizations (thus reflecting more of a condition of the general population than something specific to the sample of employees studied), even more helpful in this regard would be PSQ data collected across a number of organizations so that normative comparisons could be made. 
Perhaps more importantly, the results possess clear implications for organizational interventions designed to increase employee pay satisfaction. Since past research has identified a number of behaviors influenced by pay satisfaction, organizations might be advised to take pay attitudes seriously. More specifically, the results of the present study strongly suggest that the antecedents of pay satisfaction differ by dimension. For example, if benefit satisfaction is perceived to be a problem, increasing the perceived link between performance and pay on the part of employees through changes in the compensation system would be futile. On the other hand, such changes may have a rather dramatic effect on pay raise satisfaction. Similarly, changing how employees perceive their pay relative to others doing similar work in other companies may alter pay level satisfaction, but would have a limited effect on the other dimensions of pay satisfaction. Thus, if the results of the present study are valid, it suggests the ideal course of action may lie in identifying the sources of pay satisfaction or dissatisfaction through the PSQ, and then considering corrective actions based on the factors most likely to influence the dimension(s) that seems to be the problem. Of course, it also is true that some of the influences identified in this study are easier to change than others. Obviously, attempting to change the age composition in one's organization is not feasible, but many of the other influences can be corrected.

The practical implications of specific links within the model tested also merit some discussion. The substantiation of some of the links (e.g., salary predicting pay level satisfaction, pay raise history and pay raise interval predicting pay raise satisfaction, salary grade predicting benefit satisfaction) support the role of compensation systems in affecting pay satisfaction. In fact, these results imply that compensation policies have implications for the specific dimensions of pay satisfaction. For example, decisions to pay above-market wages, or to space out pay raise intervals, presumably will affect the relevant dimensions of pay satisfaction. Thus, in considering various compensation policies, organizations may be well-advised to consider the effects of these policies on pay satisfaction dimensions in addition to issues more commonly considered (e.g., cost savings, applicant attraction, etc.).

It is also worth noting that attitudes about the performance appraisal system and performance-pay contingencies predicted not only the hypothesized dimensions, but results from the alternative model testing suggested that they predicted other dimensions as well (although not as strongly as they predicted their hypothesized dimensions). This suggests that these variables deserve special attention when organizations examine the antecedents of compensation satisfaction. Altering these may 
not only increase pay raise and structure/administration satisfaction, but may also have a residual effect on other dimensions of pay satisfaction.

\section{Conclusions}

In sum, the present study provided evidence that pay satisfaction is multidimensional in the manner hypothesized by $\mathrm{H}$. Heneman and Schwab (1985). The results suggest that the dimensions of pay satisfaction are distinct and are differentially influenced by factors that are consistent with expectations. The results possess practical applications for organizations interested in pay satisfaction, and suggest areas where future research might further inform practitioners and researchers on this important topic.

\section{REFERENCES}

Ash RA, Dreher GF, Bretz RD. (1987, April). Dimensionality and stability of the Pay Satisfaction Questionnaire. Paper presented at the Second Annual Conference of the Society for Industrial and Organizational Psychology, Atlanta.

Barringer MW, Milkovich GT, Mitchell OS. (1991). Predicting employee health selections in a flexible benefits environment (Working Paper \#91-22). Ithaca, NY: Cornell University, Center for Advanced Human Resource Studies.

Berger CJ, Schwab DP. (1980). Pay incentives and pay satisfaction. Industrial Relations, 19, $206-211$.

Bobko P. (1990). Multivariate correlational analysis. In Dunnette MD, Hough LM (Eds.), Handbook of industrial and onganizational psychology (2nd ed., Vol. 1, pp. 637-686). Palo Alto, CA: Consulting Psychologist Press.

Bollen KA. (1989). Structural equations with latent variables. New York: Wiley.

Brooke PP, Russell DW, Price JL. (1988). Discriminant validation of measures of job satisfaction, job involvement, and organizational commitment. Joumal of Applied Psychology, 73, 139-145.

Carraher SM. (1991). A validity study of the Pay Satisfaction Questionnaire (PSQ). Educational and Psychological Measurement, 51, 491-495.

Dreher GF. (1980). Salary satisfaction and community costs. Industrial Relations, 19, 340344.

Dreher GF, Ash RA, Bretz RD. (1988). Benefit coverage and employee cost: Critical factors in explaining compensation satisfaction. PERSONNEL PSYCHOLOGY, 41, 237254.

Dyer L, Theriault R. (1976). The determinants of pay satisfaction. Joumal of Applied Psychology, 61, 596-604.

Folger R, Konovsky MA. (1989). Effects of procedural and distributive justice on reactions to pay raise decisions. Academy of Management Joumal, 32, 115-130.

Futrell CM. (1978). Effects of pay disclosure on pay satisfaction for sales managers: A longitudinal study. Academy of Management Joumal, 21, 140-144.

Gerhart BA, Judge TA. (1991). Measures of new constructs or old ones?: The case of job satisfaction and organizational commitment (Working paper \#91-10). Ithaca, NY: Cornell University, Center for Advanced Human Resource Studies. 
Gerhart BA, Milkovich GT. (1992). Employee compensation: Research and practice. In Dunnette MD, Hough LM (Eds.), Handbook of industrial and organizational psychology (2nd ed., Vol. 3, pp. 481-569). Palo Alto, CA: Consulting Psychologist Press.

Hays WL. (1980). Statistics (3rd ed.). New York: Holt, Rinehart, \& Winston.

Hemmasi M, Graf LA, Lust JA. (1992). Correlates of pay and benefit satisfaction: The unique case of public university faculty. Public Personnel Management, 21, 429-443.

Heneman HG III. (1985). Pay satisfaction. In Rowland KM, Ferris GR (Eds.), Research in personnel and human resources management (Vol. 3, pp. 115-139). Greenwich, CT: JAI Press.

Heneman HG III, Schwab DP. (1979). Work and rewards theory. In Yoder D, Heneman HG Jr. (Eds.), ASPA handbook of personnel and industrial relations (Ch. 6, pp. 122). Washington, DC: Bureau of National Affairs.

Heneman HG III, Schwab DP. (1985). Pay satisfaction: Its multidimensional nature and measurement. International Journal of Psychology, 20, 129-141.

Heneman RL, Greenberger DB, Strasser S. (1988). The relationship between pay-forperformance perceptions and pay satisfaction. PERSONNEL PSYCHOLOGY, 41, 745761.

James LR, Mulaik SA, Brett JM. (1982). Causal analysis: Assumptions, models, and data. Beverly Hills: Sage.

Jöreskog KG, Sörbom D. (1989). LISREL 7: A guide to the progräm tuxd applications. Chicago: SPSS Inc.

Jurgensen CE. (1978). Job preferences (What makes a job good or bad?). Joumal of Applied Psychology, 50, 479-487.

Lawler.EE III. (1971). Pay and organizational effectiveness. New York: McGraw-Hill.

Locke EA. (1976). The nature and causes of job satisfaction. In Dunnette MD (Ed.), Handbook of industrial and onganizational psychology (pp. 1297-1343). Chicago: Rand McNally.

Long JS. (1983). Covariance structure models: An introduction to LISREL. Beverly Hills: Sage.

Mathieu JE, Farr JL. (1991). Further evidence for the discriminant validity of measures of organizational commitment, job involvement, and job satisfaction. Joumal of Applied Psychology, 76, 127-133.

Miceli MP, Jung IJ, Near JP, Greenberger DB. (1991). Predictors and outcomes of reactions to pay-for-performance plans. Joumal of Applied Psychology, 76, 508-521.

Miceli MP, Lane MC. (1991). Antecedents of pay satisfaction: A review and extension. In Ferris GR, Rowland KM (Eds.), Research in personnel and human resources management (Vol. 9, pp. 235-309). Greenwich, CT: JAI Press.

Milkovich GT, Newman J. (1990). Compensation (3rd ed.). Plano, TX: Business Publications.

Motowidlo SJ. (1982). Relationship between self-rated performance and pay satisfaction among sales representatives. Joumal of Applied Psychology, 67, 209-213.

Mulvey PW, Miceli MP, Near JP. (1992). The Pay Satisfaction Questionnaire: A confirmatory factor analysis. Joumal of Social Psychology, 132, 139-141.

Orpen C, Bonnici J. (1987). A factor analytic investigation of the Pay Satisfaction Questionnaire. Joumal of Social Psychology, 127, 391-392.

Rice RW, Phillips SM, McFarlin DB. (1990). Multiple discrepancies and pay satisfaction. Joumal of Applied Psychology, 75, 386-393.

Ronan WW, Organt GJ. (1973). Determinants of pay and pay satisfaction. PERSONNEL PSYCHOLOGY, 26, 503-520.

Scarpello V, Campbell JP. (1983). Job satisfaction: Are all the parts there? PERSONNEL PSYCHOLOGY, 36, 577-600. 
Scarpello V, Huber V, Vandenberg RJ. (1988). Compensation satisfaction: Its measurement and dimensionality. Journal of Applied Psychology, 73, 163-171.

Scholl R, Cooper EA, McKenna JF. (1987). Referent selection in determining equity perceptions: Differential effects on behavioral and attitudinal outcomes. PERSONNEL PSYCHOLOGY, 40, 113-124.

Schwab DP. (1980). Construct validity in organizational behavior. In Staw BM, Cummings LL (Eds.), Research in onganizational behavior (Vol. 2, pp. 3-43). Greenwich, CT: JAI.

Schwab DP, Wallace MJ Jr. (1974). Correlates of employee satisfaction with pay. Industrial Relations, 13, 78-89.

Smith PC, Kendall L, Hulin CL. (1969). The measurement of satisfaction in work and retirement. Chicago: Rand McNally.

Sweeney PD, McFarlin DB, Inderrieden EJ. (1990). Using relative deprivation theory to explain satisfaction with income and pay level: A multistudy examination. Academy of Management Joumal, 33, 423-436.

Taubman P, Rosen R. (1982). Healthiness, education, and marital status. In Fuchs VR (Ed.), Economic aspects of health (pp. 121-140). Chicago: University of Chicago Press.

Taylor GS, Vest MJ. (1992). Pay comparisons and pay satisfaction among public sector employees. Public Personnel Management, 21, 445-454.

Weiss DJ, Dawis RV, England GW, Lofquist LH. (1967). Manual for the Minnesota Satisfaction Questionnaire. Minneapolis: Industrial Relations Center, University of Minnesota. 
Copyright of Personnel Psychology is the property of Blackwell Publishing Limited and its content may not be copied or emailed to multiple sites or posted to a listserv without the copyright holder's express written permission. However, users may print, download, or email articles for individual use. 